\title{
ISSUES MANAGEMENT PROGRAM MANUAL
}

\author{
LBNL/PUB-5519 (1), Rev. 0
}

Effective Date:

\author{
Ernest Orlando Lawrence \\ Berkeley National Laboratory
}




\section{REVISION HISTORY}

\begin{tabular}{|l|l|l|}
\hline Revision & Date & Revision Description \\
\hline & & \\
\hline & & \\
\hline & & \\
\hline
\end{tabular}




\section{TABLE OF CONTENTS}

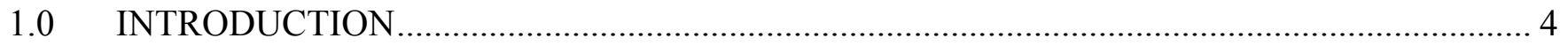

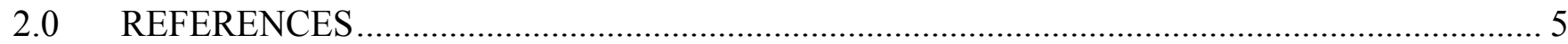

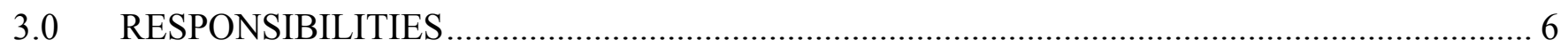

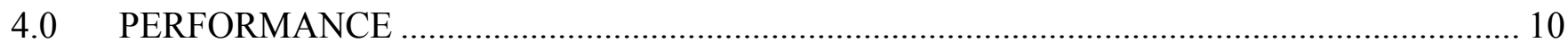

5.0 SIGNIFICANT ADVERSE CONDITIONS, PAAA NTS-REPORTABLE INCIDENTS, ORPS CATEGORY 1 OR 2 REPORTABLE INCIDENTS, AND TYPE A OR B INCIDENTS .......... 16

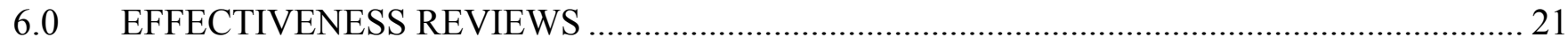

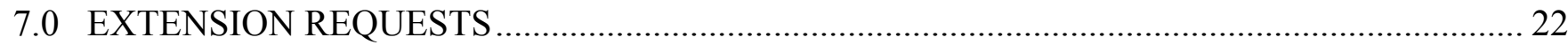

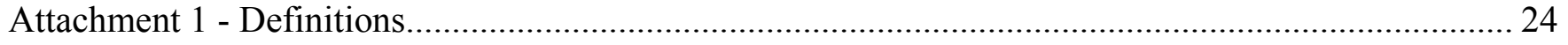

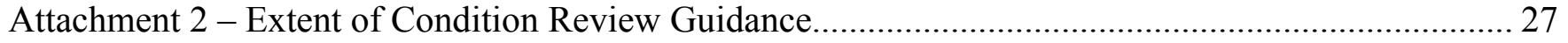

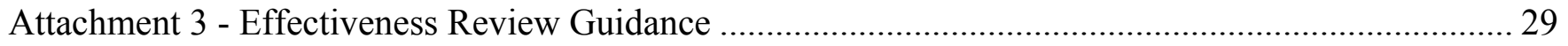

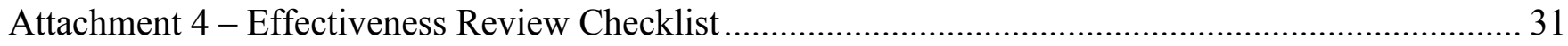

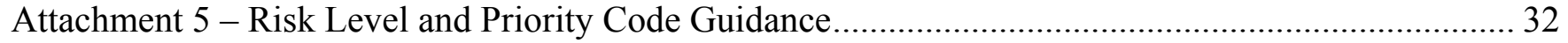




\subsection{INTRODUCTION}

The Lawrence Berkeley National Laboratory (LBNL) Issues Management Program encompasses the continuous monitoring of work programs, performance and safety to promptly identify issues to determine their risk and significance, their causes, and to identify and effectively implement corrective actions to ensure successful resolution and prevent the same or similar problems from occurring.

This document describes the LBNL Issues Management Program and prescribes the process for issues identification, tracking, resolution, closure, validation, and effectiveness of corrective actions. Issues that are governed by this program include program and performance deficiencies or nonconformances that may be identified through employee discovery, internal or external oversight assessment findings, suggested process improvements and associated actions that require formal corrective action. Issues may also be identified in and/or may result in Root Cause Analysis (RCA) reports, Price Anderson Amendment Act (PAAA) reports, Occurrence Reporting and Processing System (ORPS) reports, Accident Investigation reports, assessment reports, and External Oversight reports. The scope of these issues may include issues of both high and low significance as well as adverse conditions that meet the reporting requirements of the University of California (UC) Assurance Plan for LBNL or other reporting entities (e.g., U.S. Environmental Protection Agency, U.S. Department of Energy).

Issues that are found as a result of a walk-around or workspace inspection that can be immediately corrected or fixed are exempt from the requirements of this document.

All LBNL personnel are responsible for the identification of issues that may require correction, improvement, or management attention and the submission of an Issues Management form via the Corrective Action Tracking System (CATS) database. A "no-fault" attitude is fostered by management to encourage their staff to report issues and nonconformances. This allows management to prioritize and focus resources in a manner that best addresses the issues having the greatest risk for:

- Posing adverse risks to the environment and human health

- Adversely impacting the quality, safety, and reliability of LBNL operations

- Affecting the ability to meet contract, environmental, health and/or safety requirements

Cognizant Managers (CMs) are responsible for ensuring analysis of issues, individually and collectively, in order to identify programmatic or system issues and to identify recurrence of issues, generic issues, trends and vulnerabilities at a lower level before significant problems result. The requirements for trend code assignment, and data collection, analysis, and trending is performed in accordance with LBNL/PUB-5519 (2), Data Monitoring and Analysis Program Manual. 
Implementation of the Issues Management process is subject to the following:

- Issues must be entered into the CATS database as soon as practical after identification, but no more than five (5) business days after identification.

- Issues entered into the CATS must be tracked through resolution in the CATS database.

- While some investigation may be required (e.g. RCA, Accident Investigations, etc.) issues must be entered into the CATS database as soon as there is reasonable confidence that the issue exists and that it can be characterized.

- If it is unclear if the issue is a program or performance deficiency, the issue should be entered into the CATS database to allow disposition by the Issues Management process.

Personnel-sensitive issues such as, but not limited to, allegations of harassment, intimidation, retaliation and discrimination and for employee/employer relationship issues are not to be entered as an issue in the CATS database. Such allegations should be identified via an appropriate alternate process such as employee relations or human resources.

Select issues may be subject to requirements in addition to those outlined in this procedure. Examples include, but are not limited to, requirements to perform an ORPS RCA.

Performance of this procedure generates the following records to be maintained in accordance with the requirements outlined in the Regulations and Procedures Manual (RPM):

- CATS database

○ Issues Management Form

- Corrective Action Data Package

- Supporting documentation such as Corrective Action Plans, Root Cause Analyses (RCAs), Effectiveness Review reports, objective evidence of issue closure, etc.

\subsection{REFERENCES}

\subsection{BASELINE DOCUMENTS}

- Department of Energy Order (DOE O) 225.1A, Accident Investigations

- DOE O 226.1, Implementation of Department of Energy Oversight Policy

- DOE O 414.1C, Quality Assurance

- DOE O 442.1A, Employee Concerns Program

- DOE O 5480.19, Conduct of Operations Requirements for DOE Facilities

- UC Assurance Plan for LBNL 


\subsection{REFERENCED DOCUMENTS}

- Regulations and Procedures Manual

- LBNL/PUB-5519 (3), Data Monitoring and Analysis Program Manual

- LBNL/PUB-5519 (2), Root Cause Analysis Program Manual

- LBNL/PUB-5519 (4), Lessons Learned and Best Practice Program Manual

- Manual for PAAA Program Communications, Oversight and Reporting Processes

- Manual for 10 CFR 851 Worker Safety \& Health Program Noncompliance Screening $\&$ Reporting Process

- Procedures for LBNL Occurrence Reporting and Processing System (ORPS)

- Radiation Protection Program for the Lawrence Berkeley National Laboratory

\subsection{RESPONSIBILITIES}

\subsection{Originator}

\subsubsection{Identifies issues}

3.1.2 Documents issues by entering them into the CATS database

3.1.3 Assists personnel in initiating and updating CATS items

3.1.4 Assists responsible parties in coordinating resolution of assigned issues

3.1.5 Tracks issues and corrective actions

3.1.6 Generates and processes status updates

3.1.7 Coordinates requests for extension of due dates

3.1.8 Develops corrective actions for workspace safety issues

3.1.9 Identifies corrective action due dates for workspace safety issues

3.1.10 Identifies responsible CMs for corrective actions 


\subsection{Approver}

3.2.1 Determines applicability of issues entered by the Originator to the Issues Management Program

3.2.2 Resolves concerns regarding the issues with the Originator

3.2.3 Determines if issues are Adverse Conditions

3.2.4 Determines if issues may require reporting to any internal or external agencies

3.2.5 Notifies affected organizations of issues

3.2.6 Reviews and approves issues

3.2.7 Requests corrective action due date extensions

3.2.8 Identifies additional reviewers, as applicable

3.2.9 Verifies closure of corrective actions, as appropriate

\subsection{Cognizant Manager (CM)}

3.3.1 Determines immediate or compensatory action, if applicable

3.3.2 Develops Corrective Action Plans (CAPs), as appropriate

3.3.3 Identifies corrective action due dates, as appropriate

3.3.4 Ensures trend code determination for each action in accordance with LBNL/PUB5519 (2).

3.3.5 Ensures corrective actions are documented in the CATS database

3.3.6 Coordinates with organizations/individuals that are assigned CAP activities

3.3.7 Determines the need for a Lessons Learned or Best Practice Briefing

3.3.8 Ensures initiation of Lessons Learned or Best Practice Briefing, if required

3.3.9 Ensures corrective actions are completed and closed by the established due dates

3.3.10 Ensures CATS entries are updated when corrective actions are modified or completed

3.3.11 Ensures objective evidence of completed corrective actions is available for review

3.3.12 Initiates Extent of Condition reviews, as applicable 
3.3.13 Initiates RCA for Significant Adverse Conditions, PAAA NTS-reportable incidents (10 CFR 851 or 10 CFR 835), ORPS category 1 or 2 incidents, and Type A and B accidents

3.3.14 Ensures Senior and affected management is notified of any Significant Adverse Conditions, PAAA NTS-reportable incidents (10 CFR 851 or 10 CFR 835), ORPS category 1 or 2 incidents, and Type A and B accidents

3.3.15 Assigns personnel to perform verification of completed corrective actions

3.3.16 Ensures personnel performing verification of completed corrective actions are independent of corrective action performance

3.3.17 Ensures corrective action data packages are complete and retained as records in accordance with the RPM

3.3.18 Initiates effectiveness reviews of completed corrective actions, as applicable

\subsection{Reviewers}

3.4.1 Reviews and approves corrective action initiation and closure

3.4.2 Identifies additional reviewers, as applicable

3.4.3 Reviews objective evidence of corrective action closure

3.4.4 Verifies completed corrective actions to ensure that the data package is complete, accurate and satisfies the corrective action(s) identified.

3.4.5 Resolves concerns about issues with CMs and other assigned parties, as appropriate

3.5 Office of Contract Assurance (OCA) Manager

3.5.1 Provides oversight for the Issues Management Program

3.5.2 Approves this procedure

3.5.3 Prepares, changes and maintains this procedure

3.5.4 Maintains the CATS database

3.5.5 Provides technical guidance to LBNL staff with regard to the Issues Management Program

3.5.6 Determines if issues meet the criteria of a Significant Adverse Condition 
3.5.7 Works with CMs to ensure notification of Senior and affected management for any Significant Adverse Conditions, PAAA NTS-reportable incidents (10 CFR 851 or 10 CFR 835), ORPS category 1 or 2 incidents, and Type A and B accidents

3.5.8 Ensures appropriate additional controls and compensatory measures are taken and documented

3.5.9 Notifies affected organizations of Significant Adverse Condition implications

3.5.10 Verifies closure of corrective actions, as appropriate

\subsection{PAAA Coordinator}

\subsubsection{Program Manager}

[A ] Determines if issues meet the criteria for PAAA NTS-Reportable incidents specific to 10 CFR 851

[ B ] Ensures appropriate additional controls and compensatory measures are taken and documented

[ C ] Notifies affected organizations of 10 CFR 851 implications

\subsubsection{Program Manager}

[ A ] In conjunction with the Radiological Control Manager (RCM), determines if issues meet the criteria for PAAA NTS-Reportable incidents specific to 10 CFR 835

[ B ] Ensures appropriate additional controls and compensatory measures are taken and documented

[ C ] Notifies affected organizations of 10 CFR 835 implications

\subsubsection{RCM}

[A ] In conjunction with the 835 Program Manager, determines if issues meet the criteria for PAAA NTS-Reportable incidents specific to 10 CFR 835

[ B ] Ensures appropriate additional controls and compensatory measures are taken and documented

[ C ] Notifies affected organizations of 10 CFR 835 implications 


\subsection{ORPS Coordinator}

3.7.1 Determines if issues meet the criteria for ORPS Category 1 or 2 reportable incidents

3.7.2 Ensures appropriate additional controls and compensatory measures are taken and documented

\subsubsection{Notifies affected organizations of the ORPS implications}

3.8 Environmental, Health, and Safety (EHS) Division Manager

3.8.1 Determines if issues meet the criteria for a Type A or B accidents

3.8.2 Ensures appropriate additional controls and compensatory measures are taken and documented

3.8.3 Notifies affected organizations of the accident implications

\subsection{PERFORMANCE}

\begin{tabular}{|c|c|c|c|c|c|c|c|c|}
\hline Section & Type of Issue & $\begin{array}{c}\text { Track to } \\
\text { Resolution }\end{array}$ & $\begin{array}{l}\text { Corrective } \\
\text { Action Plan }\end{array}$ & $\begin{array}{c}\text { Root } \\
\text { Cause } \\
\text { Analysis }\end{array}$ & $\begin{array}{l}\text { Extent of } \\
\text { Condition }\end{array}$ & $\begin{array}{l}\text { Verify } \\
\text { Closure }\end{array}$ & $\begin{array}{c}\text { Effectiveness } \\
\text { Review }\end{array}$ & $\begin{array}{l}\text { Lessons } \\
\text { Learned }\end{array}$ \\
\hline 4.1 & $\begin{array}{l}\text { Workspace Safety } \\
\text { Issues }\end{array}$ & $\mathrm{X}$ & -- & -- & - & $\mathrm{X}$ & - & DBM \\
\hline 4.2 & Adverse Conditions & $\mathrm{X}$ & DBM & DBM & DBM & $\mathrm{X}$ & DBM & DBM \\
\hline 4.3 & $\begin{array}{l}\text { Significant Adverse } \\
\text { Conditions }\end{array}$ & $\mathrm{X}$ & $\mathrm{X}$ & $\mathrm{X}$ & $\mathrm{X}$ & $\mathrm{X}$ & $\mathrm{X}$ & DBM \\
\hline 4.3 & $\begin{array}{l}\text { NTS }(835 / 851) \\
\text { Reportable Incidents }\end{array}$ & $\mathrm{X}$ & $\bar{X}$ & $\mathrm{X}$ & $\mathrm{X}$ & $\mathrm{X}$ & $\mathrm{X}$ & DBM \\
\hline 4.3 & $\begin{array}{l}\text { ORPS Category } 1 / 2 \\
\text { Reportable Events }\end{array}$ & $\mathrm{X}$ & $\mathrm{X}$ & $\mathrm{X}$ & $\mathrm{X}$ & $\mathrm{X}$ & $\mathrm{X}$ & DBM \\
\hline 4.3 & Type A/B Accidents & $\bar{X}$ & $\mathrm{X}$ & $\mathrm{X}$ & $\bar{X}$ & $\bar{X}$ & $\mathrm{X}$ & DBM \\
\hline
\end{tabular}

$\mathrm{DBM}=$ Determined by Management 


\section{NOTE}

One CATS database entry is separately completed for each corrective action item so it may be tracked to completion on an individual basis.

Issues that are not considered Adverse Conditions do not require a Corrective Action Plan (CAP).

\subsection{WORKSPACE SAFETY ISSUES}

\section{Originator}

4.1.1 Document the issue in the CATS database by entering and saving the following data:
[A] Date of discovery
[B] Location
[C] Building, if applicable
[D] Issue Category
[E] Risk Level (See Attachment 5 for guidance)
[F] Significance Code (See Attachment 5 for Guidance)
[G] Issue Description in sufficient detail to allow confirmation that the issue has been resolved
[H] Corrective Action in sufficient detail so it is understood what needs to be done to resolve the issue
[I] Corrective Action Due Date
[J] Institutional or Non-institutional Issue Determination
[L] Work Request Requirement
[M] Project ID, if applicable
[N] Responsible CM
[O] Initiator of the issue

4.1.2 Route for approval. 
Approver

4.1.3 Upon electronic notification for approval of the issue, perform the following:

[A] Discuss the issue with the initiator to develop a clear understanding of the scope and severity of the issue and to assure the issue is correctly defined and reflected in the CATS database entry.

[B] Resolve any concerns with the issue with the Originator.

[C] Approve the issue.

$\mathrm{CM}$

4.1.4 Verify satisfactory completion of the corrective action.

4.1.5 Document closure of corrective action electronically in the CATS database.

\subsection{ADVERSE CONDITIONS}

Originator

4.2.1 Document the issue in the CATS database by entering and saving the following data:

[A] Date of discovery

[B] Location, if applicable

[C] Building, if applicable

[D] Risk Level (See Attachment 5 for Guidance)

[E] Significance Code (See Attachment 5 for Guidance)

[F] Issue Category

[G] Assessment Type, if applicable

[H] Assessment Number/Title, if applicable

[I] Assessment Finding Number, if applicable

[J] Description of the issue in sufficient detail to allow later confirmation that the issue has been resolved

[K] Requirement violated (if known) 
[L] The standard, order, or regulation number and section or step of the requirement that was violated (if known)

\section{[M] Responsible CM}

[N] Initiator of the issue

4.2.2 Route for approval.

\section{Approver}

4.2.3 Upon receipt of the electronic notification for approval of the issue, determine if the issue is valid and applicable to the Issues Management Program.
[A] If "YES", GO TO Step 4.2.4.
[B] If "NO", "Deny" the issue, and exit this document.

4.2.4 Discuss the issue with the initiator to develop a clear understanding of the scope and severity of the issue and to assure the issue is correctly defined and reflected in the CATS database entry.

4.2.5 Resolve any concerns with the issue with the Originator.

4.2.6 Determine if any immediate or compensatory actions are required to protect personnel and equipment from imminent danger, and report to Emergency Response, if needed.

4.2.7 Determine if the issue requires reporting to any external agencies.

4.2.8 Ensure any interim actions taken are documented in the CATS database entry.

4.2.9 Determine if the issue is a potential Significant Adverse Condition.

[A] If "YES", perform the following:

- Notify the OCA Manager.

- Determine and notify the CM.

- $\quad$ GO TO Step 5.1.

[B] If "NO”, GO TO STEP 4.2.10. 
4.2.10 Determine if the issue is a potential PAAA-Reportable Incident specific to $10 \mathrm{CFR}$ 851

[A] If "YES", perform the following:

- Notify the 851 Program Manager.

- Determine and notify the CM.

- $\quad$ GO TO Step 5.9.

[B] If "NO", GO TO STEP 4.2.11.

4.2.11 Determine if the issue is a potential PAAA-Reportable Incident specific to $10 \mathrm{CFR}$ 835

[A] If "YES", perform the following:

- Notify Radiological Control Manager (RCM) and the PAAA Coordinator.

- Determine and notify the CM.

- GO TO Step 5.15.

[B] If "NO”, GO TO STEP 4.2.12.

4.2.12 Determine if the issue is a potential ORPS-Reportable Incident

[A] If "YES", perform the following:

- Notify the ORPS Coordinator.

- Determine and notify the CM.

- $\quad$ GO TO Step 5.21.

[B] If "NO", GO TO STEP 4.2.13.

4.2.13 Determine if the issue is a potential Type A or B accident

[A] If "YES", perform the following:

- Notify the EHS Division Manager.

- Determine and notify the CM.

- GO TO Step 5.27.

[B] If "NO”, GO TO STEP 4.2.14.

\section{NOTE}

At management's discretion, findings that are a result of a formal assessment may require a CAP.

4.2.14 Determine if the issue requires a CAP.

[A] If "YES", enter the Corrective Action (i.e. "Develop a corrective action plan.") and the due date in the CATS database, then GO TO Step 4.2.15. 
[B] If "NO”, GO TO STEP 4.2.15.

4.2.15 Electronically approve the issue.

\section{NOTE}

If a CAP is determined to be required per management, reviewers are required as follows:

- Adverse Condition: OCA

- PAAA Internally -Reportable Incidents:

- 10 CFR 851 NTS-Reportable: 851 Program Manager

- 10 CFR 835 incidents requiring RSC reporting: 835 Program Manager and RCM

- ORPS Category 3 Reportable events: ORPS Coordinator

- Formal Assessments: Lead Assessor

$\mathrm{CM}$

4.2.16 Upon notification of a CATS database entry, if a CAP is required, develop a CAP that addresses the following:

[A] The apparent cause of the issue

\section{NOTE}

The extent of condition may be addressed as part of the CAP or in the RCA report.

[B] The extent of condition in accordance with Attachment 2, Extent of Condition Review Guidance

[C] Action(s) necessary to resolve the issue (including immediate, compensatory, long or short tem actions and discretionary actions)

[D] Action(s) to prevent recurrence

[E] Responsible Person(s) for a particular corrective action

[F] The expected completion date for each corrective action

\section{NOTE}

If a corrective action has multiple tasks, identify each corrective action as a separate entry in the CATS database, and the correlating task number assigned to each entry. The trend code for each task will be the same as the higher-tier corrective action.

4.2.17 Ensure corrective action information is entered into CATS, including the trend code for each corrective action in accordance with LBNL/PUB-5519 (3).

4.2.18 Coordinate the overall response by organizations/individuals having assigned CAP activities. 
4.2.19 Determine if Lessons Learned need to be submitted in accordance with LBNL/PUB-5519 (4).

4.2.20 When all required corrective actions are complete, verify satisfactory completion of actions taken by reviewing the objective evidence.

4.2.21 Submit the objective evidence of closure to the appropriate party(ies) for review, as applicable.

\section{NOTE}

Issues that are a result of a formal internal assessment require Lead Assessor review and approval prior to closure.

Reviewer

4.2.22 Review the objective evidence of corrective action closure to verify that the data package is complete, accurate and satisfies the corrective action(s) identified.

4.2.23 If the data package is incomplete, resolve issues with the CM.

4.2.24 If the data package is complete, electronically document verification of the issue in the CATS database

CM

4.2.25 Upon review completion, if applicable, document closure of corrective action electronically in the CATS database.

4.2.26 Ensure retention of Corrective Action data package in accordance with the Division records requirements

4.2.27 If no further action is required, or the actions previously taken have effectively addressed the issue, document the actions taken.

\subsection{SIGNIFICANT ADVERSE CONDITIONS, PAAA NTS-REPORTABLE INCIDENTS, ORPS CATEGORY 1 OR 2 REPORTABLE INCIDENTS, AND TYPE A OR B INCIDENTS}

\section{Significant Adverse Conditions}

OCA Manager

5.1 Determine if the issue meets the criteria for Significant Adverse Condition (see Attachment 1 - Definitions).

[A ] If yes, then GO TO step 5.2. 
[ B ] If no, then GO TO step 4.2.9 to reevaluate the issue.

5.2 Initiate appropriate compensatory actions.

5.3 Ensure that the appropriate additional controls and compensatory measures are documented.

5.4 Notify affected organizations.

$\mathrm{CM}$

5.6 Evaluate the issue and apply immediate or compensatory action(s) to correct the condition(s) that caused the suspension of work.

5.7 Discuss the issue with senior management and affected organizations.

5.8 GO TO Step 5.33.

\section{CFR 851 PAAA NTS Reportable Incidents}

851 Program Manager

5.9 Determine if the issue meets the criteria for a PAAA reportable incident specific to 10 CFR 851 in accordance with Manual for 10 CFR 851 Worker Safety \& Health Program Noncompliance Screening \& Reporting Process.

[A ] If yes, then GO TO step 5.10.

[ B ] If no, then GO TO step 4.2.9 to reevaluate the issue.

5.10 Ensure that the appropriate additional controls and compensatory measures are documented.

5.11 Notify affected organizations.

$\mathrm{CM}$

5.12 Evaluate the issue and apply immediate or compensatory action(s) to correct the condition(s)

5.13 Discuss issue with senior management and affected organizations

5.14 GO TO Step 5.33. 


\section{CFR 835 PAAA NTS Reportable Incidents}

$\mathrm{RCM}$

5.15 In conjunction with the 835 Program Manager, determine if the issue meets the criteria for PAAA reportable incident specific to 10 CFR 835 in accordance with Manual for PAAA Program Communications, Oversight and Reporting Processes.

[A ] If yes, then GO TO step 5.16.

[ B ] If no, then GO TO step 4.2.9 to reevaluate the issue.

5.16 Ensure that the appropriate additional controls and compensatory measures are documented.

5.17 Notify affected organizations.

$\mathrm{CM}$

5.18 Evaluate the issue and apply immediate or compensatory action(s) to correct the condition(s).

5.19 Discuss issue with senior management and affected organizations.

5.20 GO TO Step 5.33.

\section{ORPS Category 1 or 2 Reportable Incidents}

ORPS Coordinator

5.21 Determine if the issue meets the criteria for an ORPS Category 1 or 2 Reportable Incident in accordance with Procedures for LBNL Occurrence Reporting and Processing System (ORPS).

\section{[A ] If yes, then GO TO step 5.22.}

[ B ] If no, then GO TO step 4.2.9 to reevaluate the issue.

5.22 Ensure that the appropriate additional controls and compensatory measures are documented.

5.23 Notify affected organizations.

$\mathrm{CM}$

5.24 Evaluate the issue and apply immediate or compensatory action(s) to correct the condition(s). 
5.25 Discuss issue with senior management and affected organizations.

5.26 GO TO Step 5.33.

\section{Type A or B Accident}

EHS Division Manager

5.27 Determine if the issue meets the criteria for a Type A or B accident in accordance with LBNL PUB 3000.

[A ] If yes, then GO TO step 5.28.

[ B ] If no, then GO TO step 4.2.9 to reevaluate the issue.

5.28 Ensure that the appropriate additional controls and compensatory measures are documented.

5.29 Notify affected organizations.

$\mathrm{CM}$

5.30 Evaluate the issue and apply immediate or compensatory action(s) to correct the condition(s).

5.31 Discuss issue with senior management and affected organizations.

5.32 GO TO Step 5.33.

\section{NOTE}

An RCA Report (RCAR) generated as a result of a Significant Adverse Condition, PAAA NTSreportable incident, ORPS Category 1 or 2 reportable event, or Type A or Type B accident is maintained as part of the CAP data package.

5.33 Ensure that an RCA is performed in accordance with LBNL/PUB-5519 (2). 


\section{NOTE}

CAP reviewers are required as follows:

- Significant Adverse Condition: OCA

- PAAA NTS-Reportable Incidents:

- 10 CFR 851 NTS-Reportable: 851 Program Manager

- 10 CFR 835 incidents requiring RSC reporting: 835 Program Manager and RCM

- ORPS Category 1 or 2 Reportable events: ORPS Coordinator

- Type A or B Accidents: EHS Division Manager

- Formal Assessments: Lead Assessor

\subsection{Identify CAP Reviewers.}

CAPS should be completed as soon as practical.

\section{NOTE}

5.35 Develop a CAP that addresses the following:

[A] The apparent cause of the issue

\section{NOTE}

The extent of condition may be addressed as part of the CAP or in the RCA report.

[B] The extent of condition in accordance with Attachment 2, Extent of Condition Review Guidance

[C] Actions necessary to resolve the issue (including immediate, compensatory, long or short tem actions and discretionary actions)

[D] Actions to prevent recurrence

[E] Action party(ies) responsible for a particular corrective action

[F] The expected completion date for each corrective action.

5.36 Route the CAP to the identified reviewers.

Reviewers

5.37 Upon receipt of the CAP, review the actions identified with the assigned CM.

5.38 Resolve issues with the CM.

5.39 Approve the CAP. 
$\mathrm{CM}$

\section{NOTE}

If a corrective action has multiple tasks, identify each corrective action as a separate entry in the CATS database, and the correlating task number assigned to each entry. The trend code for each task will be the same as the higher-tier corrective action.

5.40 Ensure corrective action information is entered into CATS, including the trend code for each corrective action in accordance with.

5.41 Determine if Lessons Learned need to be submitted in accordance with LBNL/PUB-5519 (4).

5.42 Coordinate the overall response by organizations/individuals having assigned CAP activities.

5.43 When all required corrective actions are complete, verify satisfactory completion of actions taken by reviewing the objective evidence.

5.44 Document closure of corrective action electronically in the CATS database.

5.45 Ensure retention of Corrective Action data package in accordance with the Division records requirements.

\subsection{EFFECTIVENESS REVIEWS}

\section{NOTE}

The effectiveness review of corrective actions should be performed during within 3 to 12 months after issue closure and are performed in accordance with Attachment 3, Effectiveness Review Guidance.

Effectiveness reviews are performed for issues that are addressed in Section 5.0.

\section{$\mathrm{CM}$}

6.1 After closure of an issue, schedule an Effectiveness Review of identified actions to preclude recurrence.

6.2 Ensure entry of this corrective action (i.e. "Perform an Effectiveness Review.") is made into the CATS database.

6.3 Determine if a performance metric or interim review needs to be established prior to the performance of the Effectiveness Review.

6.4 Ensure the results of the Effectiveness Review are documented. 
6.5 If the Effectiveness Review determined that the actions to preclude recurrence were ineffective, ensure the following is performed:

6.5.1 Initiate a new CATS entry in accordance with this document.

6.5.2 Identify that the issue is being generated as a result of an Effectiveness Review.

6.5.3 Identify the CATS ID number for which the Effectiveness Review was performed.

6.5.4 Document the CATS ID number generated in the Effectiveness Review report.

6.6 Compile a data package including a copy of the closed Effectiveness Review and any supporting documentation.

6.7 Ensure that the data package is maintained as a record in accordance with LBNL Record Requirements.

\subsection{EXTENSION REQUESTS}

Initiator

7.1 For those issues/conditions that are not Significant Adverse Conditions, PAAA NTSreportable incidents, ORPS Category 1 or 2 reportable events, Type A or B accidents or Formal Assessment Findings, if an extension is needed to change a due date for a corrective action item already in CATS, then perform the following:

7.1.1 With concurrence from the Responsible CM, complete the Extension Request and provide justification in CATS and save to update the data.

7.1.2 Notify affected organizations of the change, if applicable.

7.1.3 Route to the appropriate Approvers Reviewer(s).

Approver(s)

7.1.4 Review the Extension Request and justification.

7.1.5 Resolve any issues with the Initiator.

7.1.6 Approve or deny the extension request.

Initiator

7.2 For issues/conditions that are Significant Adverse Conditions, PAAA NTS-reportable incidents, ORPS Cat. 1 or 2 reportable events, Type A or B accidents, or Formal Assessment findings, perform the following: 
7.2.1 Discuss extension justification and obtain approval from the following organizations:

- Significant Adverse Condition: OCA and Division Manager

- PAAA NTS Reportable (10 CFR 851): 851 Program Manager

- PAAA NTS Reportable (10 CFR 835): 835 Program Manager and RCM

- ORPS Category 1 or 2 Reportable: ORPS Coordinator

- Type A or B Accidents: EHS Division Manager

- Formal Assessments: Lead Assessor

7.2.2 Complete the Extension Request and provide justification in the CATS database and save to update data.

7.2.3 Notify affected organizations of the change, if applicable.

7.2.4 Route to the appropriate Approver(s).

Approver(s)

7.2.5 Review the Extension Request and justification.

7.2.6 Resolve any issues with the Initiator.

7.2.7 Approve or deny the extension request. 


\section{Attachment 1 - Definitions}

Adverse Condition - Adverse Conditions are program- or performance-related deficiencies (e.g. failure to follow a procedure/instruction, a procedure that does not address all appropriate the requirements, failure to complete required training, and formal assessment findings or concerns, etc.)

Approver - A generic term used to identify individuals who approve issues, corrective actions, corrective action plans, objective evidence, etc.

Cognizant Manager - The Manager responsible for ensuring that corrective actions are effectively implemented.

Corrective Action - An action that may eliminate a detected nonconformity or eliminates the cause of a detected nonconformity resulting in the prevention or significant reduction in the likelihood of the same problem occurring again

Corrective Action Plan (CAP) - A formal, documented plan developed by the responsible Cognizant Manager that addresses how an issue will be controlled and resolved through closure. Elements of a CAP include: immediate/compensatory measures taken to bring a process or program back into control, the apparent cause of issue, extent of condition of the issue, actions necessary to resolve the issue, actions necessary to prevent recurrence of the issue, the name of the responsible person(s) for a particular corrective action and the expected completion date for each corrective action.

Effectiveness Review - A review performed by the CM within a set period of time after the Issue is closed to determine the effectiveness of any actions taken to preclude recurrence of the issue. The review should confirm that the completed corrective actions to preclude recurrence are institutionalized, that occurrence of similar issue(s) due to similar cause(s) has been prevented and that the actions taken have not produced unintended consequences.

Extent of Condition - The extent to which an identified issue has the potential to impact other activities, projects, programs, facilities, organizations or processes or has done so in the past.

Formal Assessment - An assessment such as internal independent audit/surveillance, MESH reviews, etc. that are performed by an assigned Lead Assessor or Assessment Team, require the generation of a formal report, identification of findings, and documented corrective action and follow-up activities. 


\section{Attachment 1 - Definitions}

Issue - A generic term used to refer to programmatic or performance deficiencies, nonconformances, regulatory or procedural noncompliances, procedure inadequacies that may be any item identified as employee concerns, adverse conditions, assessment findings, external oversight findings, suggested process improvements and associated actions that require formal corrective action. This includes, but is not limited to, a failure, defect, deviation, malfunction, deficiency, nonconformance of plant equipment, materials, procedures, personnel safety concerns or events which have or could have an effect on the safe, reliable, or efficient operation of the Laboratory, or which involve a failure to be in compliance with requirements or management expectations. In addition, it may be a question, request for evaluation, suggestion for improvement, or management or division initiative.

Issue Category - A general category in which an issue may fall. Examples include: Workspace Safety, Safety Program, Emergency Response, Custodial Services, Financial Management, Cyber Security, Subcontracting, Ethics etc.

Originator - A generic term used to identify the individual who enters the issue and corrective action information into the CATS database.

Reviewer - A generic term used to identify individuals who review issues, corrective actions, corrective action plans, objective evidence, etc. Reviewers may also be required to approve these items. (e.g. SMEs, assessors, designated independent parties)

Root Cause - The cause of the Adverse Condition that, if corrected, will preclude recurrence or greatly reduce the probability of recurrence of the same or similar adverse conditions(s). The root cause does not apply to the identified condition only, but has generic implications to a broad group of possible occurrences and is the most fundamental aspect of the cause that logically can be identified and corrected.

Significant Adverse Condition - meets one or more of the following:

- If uncorrected, could lead to a serious effect safety/operability of the Lab

- The ability to operate the Lab or maintain effective implementation of the Assurance Program

- Requires immediate notification of regulatory entities (e.g., U.S. Nuclear Regulatory Commission)

- Indicates a significant failure or breakdown in the implementation of Assurance Program requirements

- Has not been resolved after repeated attempts

- Is identified in items or activities important to safety and compromises the ability to prevent or mitigate the consequences of an accident, thereby presenting a significant hazard to safety and health of workers and/or the public

- Constitutes an adverse trend or inclination over an extended period of time, as determined by formal performance evaluation and data/trend analysis. 


\section{Attachment 1 - Definitions}

Verification - The act of reviewing, checking or otherwise determining and documenting whether the objective evidence of corrective actions satisfies the issue and whether they have been implemented as required. Verification is performed by someone who did not perform the work associated with the issue. 


\section{Attachment 2 - Extent of Condition Review Guidance}

An extent of condition review is a process by which LBNL can identify the potential for an issue to exist in other activities, processes, programs, organizations etc., and determine whether it has occurred elsewhere and if the same root or underlying causes of the issue may be affecting performance in other applications. Extent of condition reviews are performed by the CM in conjunction with Subject Matter Experts (SMEs) and other technically competent facility personnel, as appropriate.

\section{Extent of Condition Review Approach}

A graded approach should be used when conducting an extent of condition review. This graded approach should be based on significance and risk factor to the LBNL as identified in the UC Assurance Plan for LBNL.

Extent of condition reviews are required for all significant issues (Significant Adverse Conditions, PAAA-NTS reportable incidents, ORPS category 1 or 2 reportable incidents, and Type A or B accidents, because of their seriousness and importance and may be documented as part of the Corrective Action Plan (CAP) or in a separate document. Extent of condition reviews for less significant issues may be initiated as the discretion of a $\mathrm{CM}$ in order to identify opportunities for improvement and to ensure corrective and preventive actions are developed.

\section{Extent of Condition Review Elements}

Areas to be covered as part of the effective extent of condition review may include the following:

- Looking for the same problem in applications, locations or facilities other than where originally found

- Looking for other manifestations of the identified root or underlying causes of the problem

- Looking for similar or related problems, or problems that can be anticipated based on the identified problem

- Reviewing prior applications of the deficient process or procedure to see if earlier deficiencies have gone unnoticed.

\section{Extent of Condition Review Steps}

During the extent of condition review, the following steps should be performed, as appropriate:

- Review the circumstances that led to the identification of the issue

- Determine the activities or facilities to which the issue applies

- Review results of investigations, critique results, cause codes

- Develop a line of inquiry or checklist based on the results for the circumstance review 


\section{Attachment 2 - Extent of Condition Review Guidance}

- Using responses to the line of inquiry or checklist identify the extent of applicability to other activities, processes, equipment, programs, facilities, operations, and organizations, etc.

- Document the results of the review in the CAP or in a separate report. 


\section{Attachment 3 - Effectiveness Review Guidance}

A graded approach should be used when conducting an effectiveness review. This graded approach should be based on significance and risk factor to the LBNL as identified in the UC Assurance Plan for LBNL.

Effectiveness Reviews are required for all significant issues (Significant Adverse Conditions, PAAANTS reportable incidents, ORPS category 1 or 2 reportable incidents, and Type A or B accidents) because of their seriousness and importance. Effectiveness Reviews for less significant issues may be initiated as the discretion of a $\mathrm{CM}$ in order to identify opportunities for improvement and to ensure corrective actions were effectively implemented.

Effective corrective actions to preclude recurrence share the following generic attributes:

1. Address the Root Cause and, if corrective actions to preclude recurrence were created for them, the primary Contributing Cause(s)

2. Are implemented as intended

3. Prevent occurrence of similar condition(s) due to similar cause(s)

4. Demonstrate endurance

5. Have not introduced negative unintended consequences

Attributes 1 and 2 are reviewed and verified during the processing of the Issue itself. The focus of the Effectiveness Review is to evaluate the corrective actions to preclude recurrence to ensure that attributes 3,4 , and 5 have been met. Identification of similar condition, in and of itself, does not indicate ineffective corrective actions to preclude recurrence.

For issues that require an RCA, the RCA report needs to address the criteria for the Effectiveness Review. The CM is responsible for reviewing the RCA report to ensure that appropriate criterion is addressed.

For issues that don't require an RCA, the CM is responsible for developing criteria to which the Effectiveness Review will adhere to. These criteria may be identified in a checklist or other means as deemed appropriate.

The recommended methods for planning and performing an Effectiveness Review are through formal self-assessment, audit or surveillance to determine effectiveness. This ensures that:

- $\quad$ Planning is appropriately documented

- Involved arties are included in the review, as needed

- Tools used in the analysis are documented 


\section{Attachment 3 - Effectiveness Review Guidance}

- $\quad$ Conditions that may need further review but do not, in and of themselves, indicate ineffective corrective actions to prelude recurrence are identified and documented.

Other acceptable methods include:

- $\quad$ Observation of work performance

- $\quad$ Use of performance measure and indicators to track and trend the number and frequency of recurrences

- $\quad$ Performance testing

- $\quad$ Personnel interviews to determine understanding and involvement with the implemented actions

If effectiveness reviews are performed outside of a formal self-assessment, audit or surveillance, the Effectiveness Review Checklist in Attachment 4 will be used.

The inputs to the Effectiveness Review should summarize the findings of the review, including a cross reference to the process used. This summary should focus on the determination of whether the corrective actions to preclude recurrence were effective and in line with the criteria used.

Establishment of a performance indicator or interim review process may also be used to monitor effectiveness in the time frame between closure of an issue and performance of the Effectiveness Review. After performance of the Effectiveness Review, the CM should consider the establishment of periodic reviews of effectiveness through self-assessments, audits and/or surveillances. 


\section{Attachment 4 - Effectiveness Review Checklist}

Date Performed:

CATS ID \#(s)

Performed by: (print name/sign)

Date:

\begin{tabular}{|l|l|l|}
\hline \multicolumn{1}{|c|}{ Criteria } & $\begin{array}{c}\text { Sat, Unsat, } \\
\text { N/A }\end{array}$ & Comments \\
\hline $\begin{array}{l}\text { Corrective actions have been adequately } \\
\text { incorporated into work processes, } \\
\text { procedures, instructions, training, etc. }\end{array}$ & & \\
\hline $\begin{array}{l}\text { Corrective actions have been appropriate } \\
\text { and adequately communicated to affected } \\
\text { personnel. }\end{array}$ & & \\
\hline $\begin{array}{l}\text { Corrective actions are understood by } \\
\text { affected personnel. }\end{array}$ & & \\
\hline $\begin{array}{l}\text { Corrective actions are implemented as } \\
\text { identified. }\end{array}$ & & \\
\hline $\begin{array}{l}\text { Corrective actions have prevented } \\
\text { recurrence of the identified issue. }\end{array}$ & & \\
\end{tabular}

Objective Evidence Reviewed: (Identify document titles, numbers, revision numbers)

Personnel Interviewed: (Identify first and last names) 


\section{Attachment 5 - Risk Level and Significance Code Guidance}

\section{Table 1 - RISK LEVELS}

\begin{tabular}{|c|c|}
\hline Risk Level & Type/Description of Issue \\
\hline High & $\begin{array}{l}\text { - Significant Adverse Condition (SAC) } \\
\text { - PAAA NTS-Reportable Incident } \\
\text { - 10CFR851 NTS-Reportable Incident } \\
\text { - 10CFR835 Incident reportable to the RCS } \\
\text { - ORPS Category } 1 \text { or } 2 \text { Incident } \\
\text { - Type A or B Accident } \\
\text { - Other Issues as designated by management }\end{array}$ \\
\hline Medium & $\begin{array}{l}\text { - Adverse Condition identified through Formal Assessment } \\
\text { - PAAA Internally-Reportable Incident } \\
\text { - } 10 \text { CFR851 Internally-Reportable Incident, as determined by management } \\
\text { - ORPS Category } 3 \text { Reportable Incident } \\
\text { - Other Issues as designated by management }\end{array}$ \\
\hline Low & $\begin{array}{l}\text { - Workspace Safety Issues that do not fall into High or Medium Risk } \\
\text { Levels } \\
\text { - Adverse conditions not identified through Formal Assessment } \\
\text { - Other issues that do not meet the thresholds identified in the High or } \\
\text { Medium risk levels. }\end{array}$ \\
\hline
\end{tabular}

Table 2 - SIGNIFICANCE CODES

\begin{tabular}{|l|l|}
\hline Significance Code & Type/Description of Issue \\
\hline $\begin{array}{l}\text { PAAA Reportable Incident } \\
\text { 10 CFR 835) }\end{array}$ & $\begin{array}{l}\text { Meets the threshold as a PAAA-reportable incident as detailed in Manual for } \\
\text { PAAA Program Communications, Oversight and Reporting Processes, June } \\
9,2005 \text { as determined by the 835 Program Manager and RCM. }\end{array}$ \\
\hline $\begin{array}{l}\text { PAAA Reportable Incident } \\
\text { (10 CFR 851) }\end{array}$ & $\begin{array}{l}\text { An issue that meets the threshold as a 10 CFR 851-Reportable incident as } \\
\text { detailed in Manual for 10 CFR 851 Worker Safety \& Health Program } \\
\text { Noncompliance Screening \& Reporting Process as determined by the } 851 \\
\text { Program Manager }\end{array}$ \\
\hline $\begin{array}{l}\text { ORPS Reportable Incident } \\
\text { - Category } 1 \text { or } 2\end{array}$ & $\begin{array}{l}\text { Meets the threshold for an ORPS-Reportable incident as detailed in the } \\
\text { Procedures for LBNL Occurrence Reporting and Processing System } \\
\text { (ORPS), as determined by the ORPS Coordinator }\end{array}$ \\
\hline $\begin{array}{c}\text { Type A or B Accident } \\
\text { Category } 3 \text { or } 4\end{array}$ & $\begin{array}{l}\text { Meets the threshold for a Type A or B incident as determined by the EH\&S } \\
\text { Division Manager }\end{array}$ \\
\hline Adverse Condition & $\begin{array}{l}\text { Is a programmatic or performance deficiency identified through formal or } \\
\text { informal assessment or self-identification such as a walk around }\end{array}$ \\
\hline
\end{tabular}

